\title{
Trends in Patient Generated Data - An Initial Review
}

\author{
Özgün Imre \\ Linköping University \\ ozgun.imre@liu.se
}

\author{
Sofie Wass \\ University of Agder \\ sofie.wass@uia.no
}

\begin{abstract}
In recent years, patient-centered care has gained significant momentum in healthcare and the patient is more involved as an active participant in data generation. In this state of the art review we identify trends in patient generated data (PGD) and areas in need of further research by reviewing papers published in the health tracks of five high-ranked IS conferences. Our results suggest that research is mostly empirically grounded and primarily focuses on sickness rather than wellness issues. There is an emphasis on chronic diseases and self-management, dealing with user motivation, and a focus mostly on mobile apps. Though technology plays an important part, there is scarce problematization of and theorization on PGD. Further studies are needed that investigate the effects of $P G D$ on patients and healthcare providers, include a wider range of issues and incorporate wearable devices more comprehensively.
\end{abstract}

\section{Introduction}

In recent years, patient-centered care has gained significant momentum and the involvement of patients as interactive partners has been acknowledged as an important element in healthcare [1], [2]. One suggestion for realizing a more patient-centered care is to implement different kinds of technologies that enable patients to take a more active role in monitoring and managing their health [3]. Studies have shown that especially chronically ill patients wish to get involved in their own healthcare process to self-manage and selfmonitor their condition [4]. With issues such as increasing healthcare costs and a rise in chronic diseases, the benefits of patient involvement and digitalization are discussed in both academia and society.

As an example, the European Commission stresses the importance of technologies that allow citizens to contribute with user-generated data to offer more personalized and useful healthcare. "It is essential to establish safeguards to allow citizens to use health and well being applications with confidence and subsequently ensure the integration of user-generated data with official medical data so that care can be more integrated, personalised and useful for patients" [5, pp. 8-9]. Fitness trackers, apps for diabetes management and sensor-based technologies in elderly homes are a few of the technologies that are argued to help realize this vision. This is not only seen in the healthcare sector but also in the fitness and wellness industry where the market for applications that support user-generated data is growing. Today the major app stores have over 250 thousand health apps [6].

The growing availability and widespread adoption of these technologies have led to a number of key informatics issues, and research has not caught up with the rapidly growing market of these services [7]. Several authors call for a need to further study the role of patient generated data [8]-[10]. It is therefore important to provide an update on the recent stage of the research on patient generated data (PGD) and to pinpoint areas that need further investigation. Thus, the aim of this study is to contribute to IS literature by providing a state of the art review of studies on PGD and identifying trends and areas in need of further research. In doing our review, we were inspired by [11], [12] and their ideas of conducting literature reviews and focused on high ranked information systems (IS) conferences.

In the next section we describe the review process, followed by section three where the results are provided. The results are discussed in the fourth section, which are summarised in the concluding and final section.

\section{Method}

We began our review by first looking into the basket of eight journals to be able to identify key terms and issues. Similar to other reviews, e.g. [13], [14], the intention was to focus on high ranked journals in IS due to their ability to influence 
researchers and practitioners cf. [15]. However, we identified few instances where PGD was the core of the study. Inspired by [11], [12] who argue that a literature review process is an iterative one, where new sources are added to the review as it progresses, we decided to focus on AIS conferences and a highly ranked AIS affiliate conference. We selected the conferences based on their high rank [16] and their faster publication process in comparison to journals. Furthermore, these conferences are general IS conferences, thus cater to a broad base, attracting a diverse range of papers on issues related to IS. Since PGD has been described as rather recent and dynamic field [7], conferences were judged to be a way to represent new trends and ongoing debates in the field.

The selected conferences included the International Conference on Information Systems (ICIS), the Americas Conference on Information Systems (AMCIS), the European Conference on Information Systems (ECIS), the Pacific Asia Conference on Information Systems (PACIS) and the Hawaii International Conference on System Sciences (HICSS).

We searched for papers published in the healthrelated tracks of the conferences and limited our review to papers published between 2010 and $2017^{1}$ in order to give a contemporary view of the research on PGD. We made an initial selection of studies by reviewing the title and the abstract of all papers published in the health-related tracks of the conferences. Studies were included in the review if they had: (1) patient generated data as a focus, (2) were complete research papers, and (3) an IT/IS component in the data generation process. Data gathered in the hospital setting - such as in sensors in the ICU unit - was not considered as PGD. We chose to exclude literature reviews, adoption research, and studies that focused on online communities with the sole purpose of providing patient support, or social networking. In the instance where a decision on inclusion could not be made solely on the title and the abstract, we retrieved the full paper. The initial selection of papers was made individually, and the result was then compared between the two authors. After discussions, we decided on inclusion or exclusion for the remaining papers. Based on these criteria, 83 papers were included in the review ${ }^{2}$.

\footnotetext{
${ }^{1}$ At the time of writing this paper (January, 2017), ICIS 2017 had not taken place, thus is excluded from this review. ICIS 2010 and ECIS 2011 did not have health tracks, and for AMCIS 2010 and PACIS 2014 we were not able to find the program information.

${ }^{2}$ For the full list of the reviewed papers, please contact the authors. An asterisk $(*)$ in the reference list indicates that the reference is included in the review sample.
}

- Total number of papers published in health tracks: 823

- $\quad$ Selected sample: 83

\subsection{Data Analysis}

To generate an initial coding scheme, a random sample of the papers were selected and read by the authors separately, and then discussed together to decide on a coding template. This template was adapted iteratively as more papers were read. In this process, we also asked our colleagues to give feedback on our coding template. One code that was generated early on but excluded due to low focus in the reviewed papers was the patient's role in designing the technology. As a result, we used the following coding scheme:

- Type of paper: conceptual, design-oriented or empirical, and theories used

- Main focus of the study: wellness, sickness or other

- Type of activity: self-tracking, selfmanagement, monitoring

- Type of disease or condition: cancer, diabetes etc.

- Type of technology studied/used: mobile app, sensor etc.

- Type of generated data: glucose levels, blood pressure etc.

- Data use by patient: internal (act on it immediate), external (healthcare professional sends intervention) or system aided

Table 1. Selected conferences and number of included papers in the review

\begin{tabular}{ccc}
\hline Conference & $\begin{array}{c}\text { Total } \\
\text { Number }\end{array}$ & $\begin{array}{c}\text { Number of included } \\
\text { papers }(\% \text { of total } \\
\text { papers in health } \\
\text { track }\end{array}$ \\
\hline ICIS & 85 & $6(7 \%)$ \\
AMCIS & 202 & $22(11 \%)$ \\
ECIS & 77 & $12(16 \%)$ \\
PACIS & 74 & $6(8 \%)$ \\
HICCS & 384 & $37(10 \%)$ \\
\hline
\end{tabular}

The selected sample was then divided between the two authors, and both authors read papers from all conferences but from different years. When we were unsure of how to code a specific paper, both authors read it and used discursive alignment to decide on the final coding. In total, we selected 83 
papers. The breakdown of the papers according to conferences is provided in Table 1 .

\section{Results}

The review shows that, there has been an increase of conference papers that deal with PGD, from only 1 instance in 2010 to 14 in 2017, with a peak of 22 papers in 2016.

\subsection{Type of papers and theories}

The majority of the papers are empirical (48 papers). In that sample, four papers adopt a mixed methods approach, four papers draw from design science, whereas 19 and 21 papers use qualitative and quantitative methods, respectively. 25 papers in our sample are design science papers that focus on designing technology or an app, and ten papers are conceptual, often generating a framework to study the use of technology or key issues to foster adoption. A breakdown of the papers by years shows that there is an increase in empirical papers over the years, whereas conceptual and design papers have more stable numbers, as shown in Figure 1.

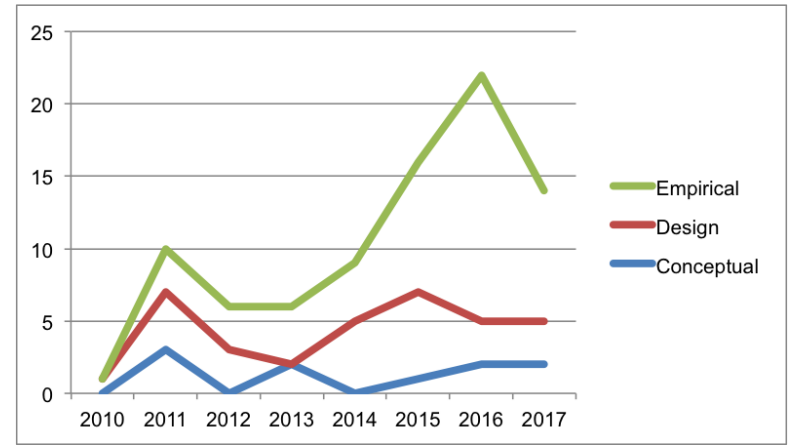

Figure 1. Type of papers over the years

In our sample, only 24 papers - mostly empirical studies - used explicitly cited theories, as described in Table 2. The technology acceptance model (TAM) is the most frequently used theoretical perspective in the reviewed papers and aims to investigate how the technologies are used by the individuals i.e. , [17], followed by two recent papers that adopt an affordance lens [18], [19]. These papers focus on how IT is viewed differently by different groups, i.e. patients and physicians. The papers that use cognitive dissonance [20], [21] shed light on how people act to reduce their cognitive dissonance due to (not) using fitness devices while the papers that employ the health belief model [22], [23] and the fogg behavior model [24], [25] study behavioural change of users and more frequent use of technology. Theories such as task-technology fit, TAM, UTAUT are used in the papers to investigate the factors that affect the adoption decisions of the users.

\section{Table 2. Theories used in the included} papers

Theories used in one paper each

Adoption; ANT; D\&M success model/Social support theory/Social presence theory; Effectuation; Information processing theory; Protection motivation theory/Task-technology fit; Self-determination theory; Social cognitive theory of self regulation; Systems' thinking; Unified theory of acceptance; Uses and gratifications theory

Theories used in two papers each

Affordance; Cognitive dissonance; Design Theory, Fogg behavior*; Health belief model**

Theories used in three papers each

Technology acceptance model

Total number of papers that cite 24

specific theories

*with Transtheoritical model of behaviour change; $* *$ with Self efficacy.

\subsection{Sickness versus wellness}

By categorizing the papers into their main focus (wellness, sickness or other) and by the disease or condition that the papers discuss we provide a picture of the trends in the research community. Below, Figure 2 provides an overview of the disease/condition that PGD is generated for or collected to assist with.

Papers that focus on PGD for sickness constitute $65 \%$ of the total sample, and the majority of the papers study general health issues (17 papers). These papers tend to have a design orientation e.g. , [26], or focus on issues like self-feedback e.g. , [17], and do not discuss a specific condition. The second largest group studies services for diabetes management, with the majority of the papers focusing in PGD that will help the patient in self-managing their diabetes, while only three papers include patients' data that is monitored to provide an intervention. The other major categories that focus on sickness are cancer, and cardiovascular/heart diseases, and other specific conditions like organ transplant issues or kidney failure.

In the wellness category, the focus is on physical health, with papers on general physical activity [27] 
and fitness-oriented activity [28], covering $74 \%$ of the 23 papers. Mental wellness is only considered by three papers, two focusing on stress management [29], [30], and one on mood [31]. The remaining papers were categorized as other type of wellness and focused on obesity [32] public health [33] and safe driving [34]. The third category, others provide only seven papers, that range from big data analytics and its effects on privacy [35], to communal health issues [36].

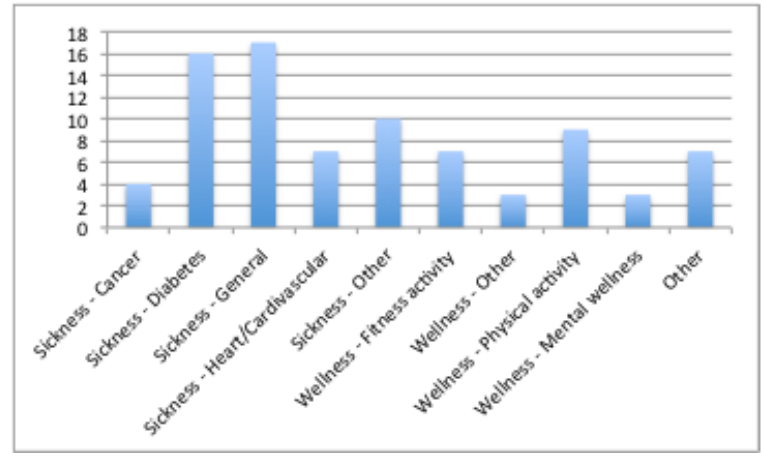

Figure 2. Distribution by PGD focus

Table 3 provides a more detailed breakdown of the focus of the studies and the intention of the PGD. It shows that self-management by the patients ( 26 papers) and distance monitoring (17 papers) of sickness-related conditions is the most common focus of the included papers. Moreover, self-tracking of wellness activities (13 papers) were frequently identified in the papers.

Table 3. Overview of papers by focus

\begin{tabular}{lccc}
\hline Focus & $\begin{array}{c}\text { Sickness } \\
(\mathrm{n})\end{array}$ & $\begin{array}{c}\text { Wellness } \\
(\mathrm{n})\end{array}$ & $\begin{array}{c}\text { Other } \\
(\mathrm{n})\end{array}$ \\
\hline Self-management & 26 & - & - \\
Distance & 17 & 3 & - \\
monitoring & & & \\
Communication & 4 & - & - \\
Self-track & 3 & 14 & - \\
Other & 5 & 4 & 7 \\
\hline
\end{tabular}

\subsection{Technology and data}

The second trend can be described by the different types of technology and applications that are under study and the type of data that is generated by the user or the patient. The majority of the studies ( 35 papers, $42 \%$ ) focus on mobile apps, either studying physical activity and fitness tracking apps or apps for patients with different conditions. Apps for physical activity or fitness tracking discuss running apps e.g.
[19] and apps for different conditions include diabetes e.g. [36], [37], but also mental health issues e.g. [31] or other conditions such as cancer [39], [40], heart failure [24] and macular degeneration [41]. Three papers focus on apps for drug administration or adherence [42]-[44] and four papers do not specify the type of mobile app studied.

The second category includes 17 studies that focus on wearable technologies, including sensors for patient vitals and activity trackers such as Apple Watches [45] and Fitbits [46]. Two papers focus on drug administration, one paper studied a digital pill with a wearable sensor [47] and one paper studied smartpumps for insulin [48]. Two papers do not specify the type of wearable technology.

The third category includes 12 studies that discuss online applications such as online platforms [18], [49] and personal health records [50], [51]. All papers in this category focus on issues related to sickness. Out of the included studies, 19 papers do not describe the studied technology. An overview of the type of technology is presented in Table 4.

Table 4. Type and focus of the technology

$\begin{array}{ll}\text { Type of } & \text { Focus of technology (n) } \\ \text { Technology } & \end{array}$

(n)

\begin{tabular}{ll}
\hline Mobile & Diabetes app: 10 \\
apps: 35 & Physical activity/fitness tracking app: 7 \\
& Drug administration/adherence app: 3 \\
& Mental health app: 3 \\
& Diet app: 3 \\
& Other conditions (heart failure, cancer, \\
& macular degeneration, reproductive \\
& problems): 5 \\
& Not specified: 4 \\
& Sensors for patient vitals: 8 \\
& Activity tracker: 5 \\
\hline Wearable & Drug administration: 2 \\
tech: 17 & Not specified: 2 \\
\hline Online & Online platform: 8 \\
applications: & Personal health records: 4 \\
12 & \\
\hline Not specified: 19 \\
\hline
\end{tabular}

Figure 3 shows that the generated data from patients or users mostly focus on blood glucose measurements and physical measures such as data on exercise, heart rate, weight, blood pressure and body temperature. Four studies include data on vital signs and three studies include data related to food such as photos of food [32] and data on consumed food [52]. Other types of generated data include mood e.g. [53], health status, pain [40], medicine use, an eye test 
[41], ingestion time [47], pictures of melanoma and a combination of different data. In total, 34 papers do not describe the type of generated data.

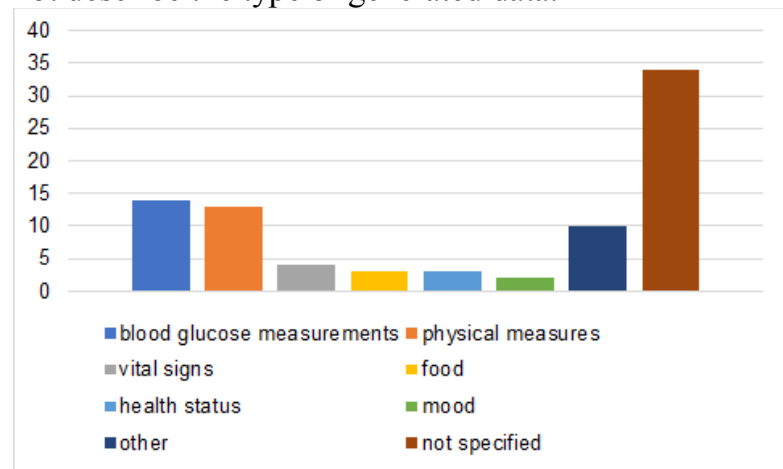

Figure 3. Different types of generated data

Moreover, 31 papers describe data that is actively generated by the user by collecting and recording data. In 17 papers, data is passively generated and in 11 papers we identified a combination of both active and passive data generation. In the end, 25 papers do not specify how data is generated. The data use by patients was divided into either external, internal, system aided or a combination of two of the previous types. In total, 41 papers (49\%) describe the data use by patients and the type of technology studied. In all categories mobile apps, wearable technologies and online applications are represented. However, as shown in figure 4, mobile apps are overrepresented in the system-aided category.

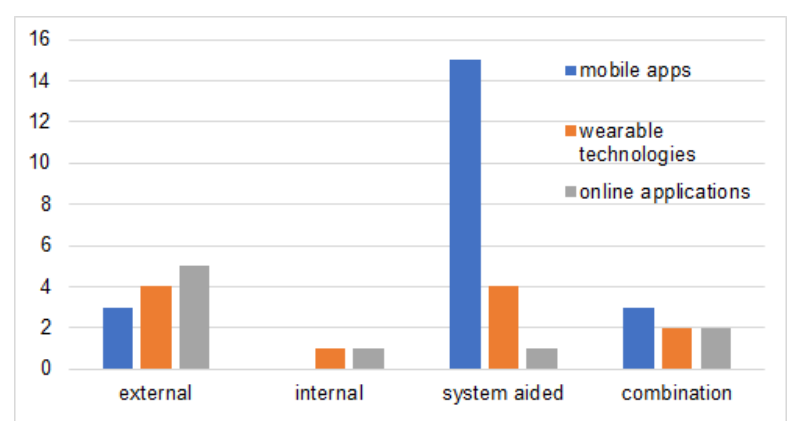

Figure 4. Type of technology and data use by patients/users

\section{Discussion}

Our review shows that the majority of the included conference papers are empirical, with a rather balanced take on qualitative and quantitative methods. One interesting aspect, however is that most of these papers study the initial use of technology: how to motivate people to adopt, how to change user behaviour, and how to build self-feedback mechanisms in the technologies to improve continued use. This coupled with the fact that $30 \%$ of the papers discuss the design of devices and applications, results in a trend that focus on the earlier stages of technologies for PGD and the design, diffusion and adoption of these technologies. Therefore, we argue that there is a need for papers that study technologies for PGD and its use in a more thorough way and that evaluates its impact and not only design issues. There are instances where cases were followed through several years with multiple publications, such as the Norwegian case presented by [25] and [53] whom studied several aspects of the technology and followed it over time.

From a theoretical perspective, there are a significant number of papers that do not mention a theory, framework or model to ground their research. Out of the 25 papers that use a theory, the reviewed papers are rather light in their theory use [55]. As noted by [56] there is an influence of IS theories on health informatics however our results show that other streams of theories seem to be used, i.e. cognitive dissonance or social cognition theory. A common trend in the included papers is that they are not focused on theory building, but rather using theories to describe technology in a specific context or use theories to explain a certain phenomenon in this context. Following the categories presented by $[57$, p. 163] the majority of papers would fit into the third and fourth categories (cf. [58]) papers that "examine phenomena in healthcare context, using theory to explain phenomena, possibly extending or building theory in this context", and papers in which "primary attention is to describing IS or IT in healthcare context with little consideration of theory".

Looking into the data, there are several issues that seem to dominate the research on PGD. Our results suggest that PGD related to sickness is more heavily investigated than wellness issues. One reason why sickness-related PGD is more prominent can be due to the constant aim to improve healthcare and the increased awareness of patient-centered care and patient involvement [59]. It is noteworthy that the majority of sickness-related papers mostly focus on specific conditions like diabetes, cancer and cardiovascular/heart diseases. These conditions are seen as major public health issues and a cause for increasing healthcare costs [60], [61]. This might be a reason why studies on diabetes, cancer and cardiovascular/heart diseases dominate the field, and result in a more focused research agenda on sicknessrelated issues. 
However, one could expect an increasing focus on wellness technologies, since fitness applications and smart watches are conveniently available to the end users, and popular. A report by IMS [62] shows that two thirds of health related apps are were wellness oriented. Whereas, with sickness-related technologies patients might need to use more complex devices, for example replacing the old glucose meter with a Bluetooth enabled glucose meter - even though as noted by [10] these devices are becoming more affordable. The high numbers of papers that discuss system-aided interventions seem to be connected to the frequent studies on mobile apps. Some studies described PGD that included an intervention from external actors such as physicians or nurses. In those cases, the type of technology was mostly wearables or online applications.

Our results show that most studies focus on mobile apps, both for wellness and sickness whereas studies on wearables and online applications are less common. One probable reason of the focus on apps instead of wearables might be the higher initial costs of these devices. However, the market analysis of wearables shows a steady increase in use, and the number of connected devices is projected to grow from 325 mil in 2016 to 926 mil in 2021 [63]. Thus, it will be interesting to investigate their effect on PGD Though technology plays an important part, a quarter of the papers did not specify the technology used. This is also shown in the type of generated data and data use by patients, in which as many as $41 \%$ and $49 \%$ of the papers did not provide a description of these elements. Thus, the included studies on PGD seem to be unspecific about the both the studied technology and the PGD. Therefore, we argue that there is a need to be more specific about the generated data and the technology studied, similar to what [64] argued when they suggested that technology should be engaged with more directly, especially if impact of the technology is to be studied. Defining the technology would then help to better investigate the effects of PGD from a more holistic perspective, such as argued by [65]. To summarize, we present suggestions on areas in need of further research.

\section{Type of paper and theory}

- Include a wider variety of theories and attempts of theory building.

- Conduct studies in the later stages of technology use, such as evaluations on the effectiveness of PGD, achievement of intended goals, use of PGD by patients and caregivers.
Sickness and wellness

- Include a wider range of health issues.

- Include other wellness-issues than physical activity and fitness, for instance mental wellness.

Technology and data

- Pursue more research that focus on wearables and sensors, such as those in smart homes.

- Conduct studies that include other measurements than blood glucose levels and physical activity.

\section{Conclusions}

The aim of this study was to provide a state of the art review of recent studies on patient generated data by identifying trends and areas in need of further research. Although our review was limited to conference papers in IS field, our results highlight trends within the field. The majority of the papers are empirically grounded, dealing with issues of motivating people to use these technologies and focusing on the early stages of technology use. The papers cover issues related to both sickness and wellness, with a focus on chronic diseases and fitness or physical activities. Self-management by patients is in focus of sickness-related papers, especially diabetes, whereas self-tracking is an identified trend in wellness-related papers. The included studies focus mostly on mobile apps and when interventions are provided to the patient it is primarily system aided. Though technology plays an important part in these studies, some of the papers do not specify the technology used.

Concerning recommendations on further research, there is a need for more studies that investigate the later stages of technology use and not only design issues. For instance, there seems to be a need for studies that evaluate the effects of PGD on patients and healthcare providers and that contribute to theorization on PGD. One way to identify these kinds of studies would be to follow the research from a more longitudinal perspective, i.e. longitudinal studies, or tracking the research papers progression from conference contributions to more substantial journal papers. Future studies should also include a wider range of health and wellness issues and incorporate wearable devices more comprehensively. Engaging with these issues more thoroughly can help to create a more nuanced understanding of the effects of PGD. 


\section{References}

[1] D. Z. Sands and J. S. Wald, "Transforming Health Care Delivery Through Consumer Engagement, Health Data Transparency, and Patient-Generated Health Information," Yearb. Med. Inform., vol. 9, no. 2014, pp. $170-176$.

[2] A. White and M. Danis, "Enhancing PatientCentered Communication and Collaboration by Using the Electronic Health Record in the Examination Room," JAMA, vol. 309, no. 22, 2013, pp. 2327-2328.

$\left[3^{*}\right] \quad$ S. Koch, "Improving quality of life through eHealth-the patient perspective," in 24th European Medical Informatics Conference, 2012.

[4] H. Bastiaens, P. Van Royen, D. R. Pavlic, V. Raposo, and R. Baker, "Older people's preferences for involvement in their own care: a qualitative study in primary health care in 11 European countries," Patient Educ. Couns., vol. 68, no. 1, 2007, pp. 33-42.

[5] European Commission, "eHealth Action Plan," 2012.

[6] Reseach2Guidence, "mHealth App Developer Economics 2016: The current status and trends of the mHealth app market," 2016. [Online]. Available: https://research2guidance.com/r2g/r2gmHealth-App-Developer-Economics-2016.pdf.

[Accessed: 16-Nov-2017].

[7] S. T. Rosenbloom, "Person-generated health and wellness data for health care," J. Am. Med. Informatics Assoc., vol. 23, no. 3, 2016, pp. 438439.

[8] G. Demiris, "Consumer health informatics: Past, present, and future of a rapidly evolving domain," Yearb. Med. Inform., no. Suppl 1, 2016, pp. S427.

[9] E. Klecun, "Transforming healthcare: Policy discourses of IT and patient-centred care," Eur. J. Inf. Syst., vol. 25, no. 1, 2016, pp. 64-76.

[10] A. M. Lai, P.-Y. S. Hsueh, Y. K. Choi, and R. R. Austin, "Present and Future Trends in Consumer Health Informatics and Patient-Generated Health Data," Yearb. Med. Inform., vol. 26, no. 1, 2017, pp. 152-159.

[11] S. K. Boell and D. Cecez-Kecmanovic, "Literature Reviews and the Hermeneutic Circle," Aust. Acad. Res. Libr., vol. 41, no. 2, 2010, pp. 129-144.

[12] S. K. Boell and D. Cecez-Kecmanovic, "A hermeneutic approach for conducting literature reviews and literature searches," Commun. Assoc. Inf. Syst., vol. 34, no, 2014, pp. 257-286.

[13] D. Arnott and G. Pervan, "A critical analysis of decision support systems research revisited: The rise of design science," J. Inf. Technol., vol. 29, no. 4, 2014, pp. 269-293.

[14] E. W. Bernroider, A. Pilkington, and J.-R. Córdoba, "Research in information systems: a study of diversity and inter-disciplinary discourse in the AIS basket journals between 1995 and 2011,” J. Inf. Technol., vol. 28, no. 1, 2013, pp.
74-89.

[15] P. B. Lowry, G. D. Moody, J. Gaskin, D. F. Galletta, S. L. Humpherys, J. B. Barlow, and D. W. Wilson, "Evaluating Journal Quality and the Association for Information Systems Senior Scholars' Journal Basket via Bibliometric Measures," MIS Q., vol. 37, no. 4, 2013, pp. 9931012.

[16] CORE, "Conference Portal," 2017. [Online]. Available: portal.core.edu.au/conf-ranks/. [Accessed: 13-Nov-2017].

$\left[17^{*}\right] \quad$ H. Kwon, K. Lee, and B. Lee, "The effects of selffeedback function on continued use of mobile personal health record application," in Proceedings of the 35th International Conference on Information Systems (ICIS), 2014, pp. 1-17.

[18*] A. Savoli and H. Barki, "A Multilevel Perspective on IT Affordances," in 24th European Conference on Information Systems (ECIS), 2016, p. P.129.

[19*] M. Yassaee and R. Winter, "Analyzing Affordances of Digital Occupational Health Systems," in Proceedings of the 50th Hawaii International Conference on System Sciences (HICSS), 2017, pp. 3567-3576.

[20*] R. Baumgart, "How Does Quantified Self Run?," in Proceedings of the 22nd Americas Conference on Information Systems (AMCIS), 2016.

[21*] R. Baumgart, "Another Step towards the Understanding of Self-Tracking: A Research Model and Pilot Test," in Proceedings of the 23rd Americas Conference on Information Systems (AMCIS), 2017, pp. 1-10.

[22*] M. Thomas, P. Narayan, and C. Christian, "A Mobile phone-Based ICT Solution for Reporting and Tracking unreported Reproductive Health Problems in the Outlier Communities of Kerala, India," in Proceedings of the European Conference on Information Systems (ECIS), 2012.

[23*] A. Ojo, S. Chatterjee, H. W. Neighbors, G. A. Piatt, S. Moulik, B. D. Neighbors, J. Abelson, C. Krenz, and D. Jones, "OH-BUDDY: Mobile Phone Texting Based Intervention for Diabetes and Oral Health Management," in Proceeding of the 48th Hawaii International Conference on System Sciences (HICSS), 2015, pp. 803-813.

[24*] A. Alluhaidan, E. Lee, N. Alnosayan, S. Chatterjee, L. Houston-Feenstra, W. Dysinger, and M. Kagoda, "Designing Patient-Centered mHealth Technology Intervention to Reduce Hospital Readmission for Heart-Failure Patients," in Proceedings of the 48th Hawaii International Conference on System Sciences (HICSS), 2015, pp. 2886-2895.

[25*] A. Hamper, "A Context Aware Mobile Application for Physical Activity Promotion," in Proceedings of the 48th Hawaii International Conference on System Sciences (HICSS), 2015, pp. 3197-3206.

[26*] P. Vassilakopoulou and M. Grisot, "Technology innovaton in the face of uncertainty: The case of 'My Health Record,'" in Proceedings of the 
European Conference on Information Systems (ECIS,) 2012, Paper 198.

[27*] E. Koskivaara, "Analysing Physical Activity behaviour with Self-Organizing Maps-a RCT Study with Polar Active.," in Proceedings of the Pacific Asia Conference on Information Systems (PACIS), 2016, Paper 22.

[28*] J. Hakkila, M. Alhonsuo, L. Virtanen, J. Rantakari, A. Colley, and T. Koivumaki, "MyData Approach for Personal Health -- A Service Design Case for Young Athletes," in Proceedings of the 49th Hawaii International Conference on System Sciences (HICSS), 2016, pp. 3493-3502.

[29*] S. Ewais and A. Alluhaidan, "Classification of Stress Management mHealth Apps Based on Octalysis Framework," in Proceedings of the 21st Americas Conference on Information Systems (AMCIS), 2015, pp. 1-8.

[30*] U. Reimer, E. Laurenzi, E. Maier, and T. Ulmer, "Mobile Stress Recognition and Relaxation Support with SmartCoping: User-Adaptive Interpretation of Physiological Stress Parameters," in Proceedings of the 50th Hawaii International Conference on System Sciences (HICSS), 2017, pp. 3597-3606.

[31*] D. Becker, V. Bremer, B. Funk, J. Asselbergs, H. Riper, and J. Ruwaard, "How to Predict Mood? Delving into Features of Smartphone-Based Data," in Proceedings of the 22nd Americas Conference on Information Systems (AMCIS), 2016, pp. 1-10.

[32*] T. Kowatsch, W. Maass, I. P. Cvijikj, D. Büchter, B. Brogle, A. Dintheer, D. Wiegand, D. DurrerSchutz, R. Xu, Y. Schutz, and D. L'AllemandJander, "Design of a Health Information System Enhancing the Performance of Obesity Expert and Children Teams," in Proceedings of the European Conference on Information Systems (ECIS), 2014.

[33*] R. Steele and A. Clarke, "A Sensor-based Learning Public Health System," in Proceedings of the 50th Hawaii International Conference on System Sciences (HICSS), 2017, pp. 3459-3468.

[34*] X. Hu, X. Li, E. C. H. Ngai, J. Zhao, V. C. M. Leung, and P. Nasiopoulos, "Health drive: Mobile healthcare onboard vehicles to promote safe driving," in Proceedings of the 48th Hawaii International Conference on System Sciences (HICSS), 2015, pp. 3074-3083.

[35*] H. Li, J. Wu, L. Liu, and Q. Li, "Adoption of Big Data Analytics in Healthcare: The Efficiency and Privacy," in Proceedings of the Pacific Asia Conference on Information Systems (PACIS) 2015, Paper 181.

[36*] D. Petrakaki, "Producing communal health through technological self-care: the emergence of digital patient activism," in Proceedings of the European Conference on Information Systems (ECIS), 2017, pp. 815-827.

[37*] A. Banerjee, R. A. Ramanujan, and S. Agnihothri, "Mobile Health Monitoring: Development and Implementation of an App in a Diabetes and Hypertension Clinic," in 49th Hawaii International
Conference on System Sciences (HICSS), 2016, pp. 3424-3436.

[38*] D. Strong, B. Tulu, E. Agu, and S. Q. He, "Design of the Feedback Engine for a Diabetes Self-care Smartphone App," in Americas Conference on Information Systems (AMCIS), 2014, pp. 1-11.

[39*] X. Chadwick, L. J. Loescher, M. Janda, and H. P. Soyer, "Mobile Medical Applications for Melanoma Risk Assessment: False Assurance or Valuable Tool?," in 47th Hawaii International Conference on System Sciences, 2014, pp. 26752684.

[40*] M. Haque, F. Kawsar, M. Adibuzzaman, and M. Uddin, "Barriers for Breast Cancer (BC) Patients in Rural Bangladesh: Design and Deployment of a Mobile based Solution," in Americas Conference on Information Systems (AMCIS), 2014.

[41*] K. Lienhard and C. Legner, "The Anatomy of Context-aware Mobile Patient Monitoring," in 36th International Conference on Information Systems (ICIS), 2015.

[42*] T. A. Majchrzak and A. Chakravorty, "Improving the Compliance of Transplantation Medicine Patients with an Integrated Mobile System," in 45th Hawaii International Conference on System Sciences (HICSS), 2012, pp. 2696-2705.

[43*] X. Liu and U. Varshney, "A Carrot \& Stick Intervention for Medication Adherence using Mobile Phone," in 22nd Americas Conference on Information Systems (AMCIS), 2016.

[44*] K. Bravhar and R. Juric, "Personalized Drug Administration to Patients with Parkinson's Disease: Manipulating Sensor Generated Data in Android Environments," in 50th Hawaii International Conference on System Sciences (HICSS), 2017.

[45*] C.-P. H. Ernst and A. W. Ernst, "The influence of privacy risk on smartwatch usage," in 22nd Americas Conference on Information Systems (AMCIS), 2016.

[46*] L. Giddens, D. Leidner, and E. Gonzalez, "The Role of Fitbits in Corporate Wellness Programs: Does Step Count Matter?," in 50th Hawaii International Conference on System Sciences (HICCS), 2017, pp. 3627-3635.

[47*] P. R. Chai, R. K. Rosen, and E. W. Boyer, "Ingestible Biosensors for Real-Time Medical Adherence Monitoring: MyTMed," in 49th Hawaii International Conference on System Sciences (HICSS), 2016, pp. 3416-3423.

[48*] R. Scheepers, H. Davis, L. Sonenberg, and S. Howard, "Consumer health ICT and the patient in the middle: adopter and/or influencer?," in 15th Pacific Asia Conference on Information Systems (PACIS), 2011.

[49*] H. Fan, R. Lederman, S. P. Smith, and S. Chang, "How Online Health Forum Users Assess UserGenerated Content: Mixed-Method Research.," in 21st European Conference on Information Systems (ECIS), 2013.

[50*] E. B. Beckjord, R. Rechis, and B. W. Hesse, "Use 
of, preferences for, and expectations regarding personal health records among people affected by cancer: results of a LIVESTRONG survey and the 2008 health information national trends survey," in 45th Hawaii International Conference on System Sciences (HICSS), 2012, pp. 2761-2769.

[51*] J. Pak and Y.-T. Song, "Health Capability Maturity Model: Person-centered Approach in Personal Health Record system.," in 22nd Americas Conference on Information Systems (AMCIS), 2016.

[52*] J.-F. Chen, L.-L. Wu, and S.-C. Chou, "Effects of Journaling Dietary Intake App on the Health Outcomes of Chronic Kidney Disease Stage 3B5," in 49th Hawaii International Conference on System Sciences (HICSS), 2016, pp. 3379-3388.

[53*] J. Kim, S. Lim, B. Lee, and J. W. Lee, "Detecting Depression of Cancer Patients with Daily Mental Health Logs from Mobile Applications," in 36th International Conference on Information Systems (ICIS), 2015.

[54*] P. Vassilakopoulou, M. Grisot, and M. Aanestad, "A Frugal Approach to Novelty: Patient-oriented Digital Health Initiatives Shaped by Afordable Losses and Alliances," in Proceedings of European Conference on Information Systems (ECIS) 2015, Paper 193.

[55] D. Avison and J. Malaurent, "Is theory king?: questioning the theory fetish in information systems," J. Inf. Technol., vol. 29, no. 4, 2014, pp. 327-336.

[56] S. Cockcroft, "Exploring the Impact of IS Theory on Health Informatics," in Proceedings of the 48th Hawaii International Conference on System Sciences (HICSS), 2015, pp. 4938-4947.

[57] M. W. Chiasson and E. Davidson, "Pushing the contextual envelope: Developing and diffusing IS theory for health information systems research," Inf. Organ., vol. 14, no. 3, 2004, pp. 155-188.

[58] D. Romanow, S. Cho, and D. W. Straub, "Riding the Wave: Past Trends and Future Directions for Health IT Research,” MIS Q., vol. 36, no. 3, 2012, pp. iii-X.

[59] S. S. Woods, N. C. Evans, and K. L. Frisbee, "Integrating patient voices into health information for self-care and patient-clinician partnerships: Veterans Affairs design recommendations for patient-generated data applications," J. Am. Med. Informatics Assoc., vol. 23, no. 3, 2016, pp. 491495.

[60] U. E. Bauer, P. A. Briss, R. A. Goodman, and B. A. Bowman, "Prevention of chronic disease in the 21 st century: elimination of the leading preventable causes of premature death and disability in the USA," Lancet, vol. 384, no. 9937, 2014, pp. 45-52.

[61] OECD, "Health at a Glance 2017: OECD Indicators," 2017. [Online]. Available: http://dx.doi.org/10.1787/health_glance-2017-en. [Accessed: 23-Nov-2017].

[62] IMS Institute for Healthcare Informatics, "Patient adoption of mHealth," 2015.

[63] Statistia, "Connected wearable devices worldwide 2016-2021", retrieved from: https://www.statista.com/statistics/487291/globalconnected-wearable-devices/

[64] W. J. Orlikowski and C. S. Iacono, "Research Commentary : Desperately Seeking the ' IT' in IT Research - A Call to Theorizing the IT Artifact," Inf. Syst. Res., vol. 12, no. 2, 2001, pp. 121-134.

[65] S. Alter, "The concept of 'IT artifact' has outlived its usefulness and should be retired now," Inf. Syst. J., vol. 25, no. 1, 2015, pp. 47-60, Jan. 